\title{
Polar localization of a bacterial chemoreceptor
}

\author{
M.R.K. Alley, Janine R. Maddock, and Lucille Shapiro \\ Department of Developmental Biology, Beckman Center, Stanford University School of Medicine, Stanford, California \\ 94305-5427 USA
}

\begin{abstract}
The bacterial chemotaxis signal transducer MCP is an integral membrane receptor protein. The chemoreceptor is localized at the flagellum-bearing pole of Caulobacter crescentus swarmer cells. Amino-terminal sequences of the MCP target the protein to the membrane while the carboxy-terminal portion of the protein is responsible for polar localization. The $C$. crescentus and Escherichia coli MCPs have highly conserved carboxy-terminal domains, and when an $E$. coli MCP is expressed in $C$. crescentus, it is targeted to the swarmer cell progeny. These results suggest that subcellular localization of a prokaryotic protein involves interaction of specific regions of the protein with unique cell sites that contain either localized binding proteins or a specific secretory apparatus.
\end{abstract}

[Key Words: Caulobacter; chemoreceptor; chemotaxis; polarity]

Received January 14, 1992; revised version accepted February 28, 1992.

The Caulobacter crescentus predivisional cell gives rise to distinctly different progeny: a stalked cell and a swarmer cell. The swarmer cell has a single polar flagellum, polar pili, and receptors for pole-specific phage. The flagellar components are synthesized in the predivisional cell and are specifically assembled at the nascent swarmer cell pole. Pilin, which is present throughout the predivisional cell (Smit 1987), is assembled at the pole of the swarmer cell upon cell division (Sommer and Newton 1988|. There are also several proteins that are synthesized in the predivisional cell that segregate to the nonmotile stalked cell. Among these are proteins involved in the heat shock response, including Lon, DnaK, and a putative RNA polymerase $\sigma$-factor (Reuter and Shapiro 1987/. We have proposed that there are at least two mechanisms used to segregate newly synthesized proteins to specific progeny cells: transcriptional localization (Gober et al. 1991a,b) and protein localization (Loewy et al. 1987). The transcription of several flagellar structural genes appears to be localized to the chromosome residing in the nascent swarmer cell portion of the predivisional cell (Milhausen and Agabian 1983; Gober et al. 1991b). However, transcriptional localization was not found for the $f l g /$ gene encoding the $29-\mathrm{kD}$ flagellin (Loewy et al. 1987) nor for the mcpA gene encoding a chemoreceptor, yet both of these proteins segregate to the swarmer cell, suggesting that sequences within the protein are responsible for localization.

The bacterial chemoreceptors are transmembrane methyl-accepting chemotaxis proteins (MCPs). The carboxy-terminal portion of these proteins is cytoplasmic and is differentially methylated and demethylated in response to ligand binding to the periplasmic portion of the protein (Krikos et al. 1983). We have shown previously that the $C$. crescentus chemoreceptors are synthesized in the predivisional cell but are segregated to the progeny swarmer cell (Gomes and Shapiro 1984). In addition, indirect evidence using membrane vesicles prepared from the poles of predivisional cells suggests that newly synthesized MCPs are localized to the nascent swarmer cell portion of the predivisional cell (Nathan et al. 1986). In this study we demonstrate directly that the chemoreceptor, encoded by $m c p A$, is localized to the pole of the swarmer cell. We also show that the methylation involved in adaption of the chemotactic response is not needed for polar localization. A region in the carboxyl terminus of the protein is responsible for polar targeting and the consequent segregation to the swarmer cell progeny. Sequences within the carboxyl terminus are conserved in C. crescentus and Escherichia coli chemoreceptor proteins, and a chemoreceptor encoded by the $E$. coli tsr gene preferentially segregates to the swarmer cell progeny when expressed in C. crescentus.

\section{Results \\ Comparison of C. crescentus and enteric chemoreceptors}

The 2.3-kb EcoRI fragment shown in Figure 1 contains the promoter for a $C$. crescentus chemotaxis operon and encodes a protein that cross-reacts with antiserum raised against the Salmonella typhimurium chemoreceptor Tar (Alley et al. 1991). The DNA sequence of this EcoRI fragment plus an adjoining 280-bp EcoRI fragment is shown 


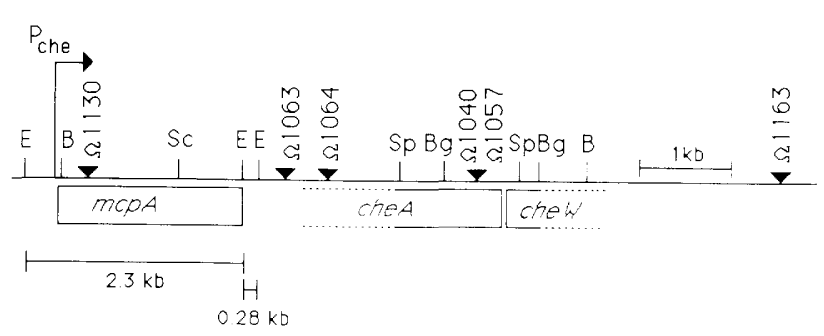

Figure 1. Restriction map of the C. crescentus chemotaxis operon. The boxes below the restriction map denote coding sequences for the genes (Alley et al. 1991). The cheA and chew genes were identified by DNA sequencing of the $1.1-\mathrm{kb} S p h \mathrm{I}$ fragment (W. Alexander, unpubl.). (V) Tn 5 insertions that result in a che ${ }^{-}$phenotype. (E) EcoRI; (B) BamHI; $(\mathrm{Bg})$ BgIII; (Sc) SacI; (Sp) SphI.

in Figure 2. The 2.3-kb EcoRI fragment contains an open reading frame (ORF) that encodes a predicted $70-\mathrm{kD}$ protein composed of 657 amino acid residues. This ORF originates just upstream of the BamHI site (Figs. 1 and 2) and ends exactly at the EcoRI site (Fig. 2). Figure 3 is a comparison of the deduced amino acid sequences of the C. crescentus $m c p A$ gene and four E. coli chemoreceptors, Tap (ecotap), Trg (ecotrg), Tsr |ecotsr|, and Tar (ccotarl, and two chemoreceptors from Enterobacter aerogenes, Tse (earots) and Tas (earota). Amino acid sequence similarities at the amino terminus are rather sparse, with the exception of the first eight amino acids. These residues are part of the first transmembrane portion (TM1), which is thought to act as a signal sequence /Gebert et al. 1988). The high sequence conservation might indicate an additional function for this region. Differences among the various chemotaxis transducers in the amino-terminal domain are expected, as this region contains the periplasmic receptor for different chemoattractants as well as the transmembrane-spanning portions of the protein. Using the Wisconsin GCG package (Devereux et al. 1984) we identified two hydrophobic regions in McpA at positions analogous to the predicted transmembrane domains of the $E$. coli chemoreceptors. A fusion protein that contains the amino terminus of McpA fused at the Sall site (betwcen TMl and TM2) to $\beta$-lactamase is membranc localized. As expected for fusions that place $\beta$-lactamase in the periplasm (BroomeSmith and Spratt 1986), strains containing this McpA$\beta$-lactamase fusion exhibit high levels of ampicillin resistance. However, a $\beta$-lactamase protein fusion that contains both predicted transmembrane domains of McpA (MCL2, Fig. 4) and is therefore predicted to localize $\beta$-lactamase cytoplasmically has a much lower level of ampicillin resistance (data not shown).

The predicted amino acid sequence of the C. crescentus McpA protein has an unusually large linker region between TM2 and the first methylation region $\mathrm{K} 1$. In addition, this region contains a string of 7 alanines at residues $312-318$, followed by a glutamine and a glutamic acid residue, reminiscent of the sequence for the R1 methylation region of several chemoreceptors. Thus, it may be that the C. crescentus chemoreceptor contains an additional methylation region. The McpA $\mathrm{Kl}$ and $\mathrm{R} 1$ methylation regions shown in Figure 3 are very similar to the enteric chemoreceptors. The $\mathrm{K} 1$ region is more highly conserved, perhaps reflecting the larger number of potential methylation sites.

A striking feature in this amino acid comparison is the large stretch of identical amino acid residues from residue 474 to 524 (Fig. 3), referred to as the highly conserved domain (HCD). The conservation of this domain among a diverse group of bacteria suggests a functional role for the region. The HCD within the $E$. coli transducer Tsr chemoreceptor has been demonstrated genetically to interact with the CheW protein (Liu and Parkinson 1991).

Segregation of McpA- $\beta$-lactamase fusions to the progeny swarmer cell

We have shown that $C$. crescentus MCPs are synthesized in predivisional cells and are then segregated to the swarmer cell progeny upon cell division (Gomes and Shapiro 1984). Analysis of membrane vesicles derived from predivisional cells showed that the $C$. crescentus MCPs preferentially accumulate at the flagellated pole of the predivisional cell (Nathan et al. 1986). To determine whether McpA segregates to swarmer cells, and if so, which portion of the protein is responsible for this segregation pattern, we constructed two chromosomal McpA- $\beta$-lactamase protein fusions, with different lengths of McpA fused to $\beta$-lactamase (Fig. 4A). The $\beta$-lactamase gene used in these fusions lacks its own signal sequence and therefore relies on the McpA protein for membrane insertion.

The longest McpA- $\beta$-lactamase fusion has the entire mcpA gene fused to $\beta$-lactamase (MCL 722), whereas the other fusion (MCL2) lacks the carboxy-terminal coding region, including the $\mathrm{HCD}$ and the $\mathrm{Rl}$ methylation region (Fig. 4A). The segregation of these two fusions to the swarmer cell upon cell division was assayed by pulselabeling predivisional cells with $\left[{ }^{35} \mathrm{~S} \mid\right.$ methionine and collecting the separated progeny after cell division (shown diagrammatically in Fig. 9, below). The protein fusions from each cell type were immunoprecipitated with anti- $\beta$-lactamase antibody. Parallel immunoprecipitations with anti-flagellin antiserum were used as a control and showed that the flagellins segregated to the swarmer cell, as reported previously (Loewy et al. 1987; Reuter and Shapiro 1987). The full-length fusion (MCL 722) segregates specifically to the swarmer cells, whereas the deletion fusion (MCL2) is distributed equally to both cell types (Fig. 4B). These results suggest that sequences within the carboxyl terminus are required for the asymmetric segregation of McpA to the progeny swarmer cell.

We determined that both fusions are membrane localized by separating membrane and cytosolic fractions from cells harboring chromosomal copies of either MCL722 or MCL2. Immunoblots with anti- $\beta$-lactamase antibody showed that both protein fusions were membrane localized (Fig. 4C), as might be expected because both fusions retain the two transmembrane domains. We 


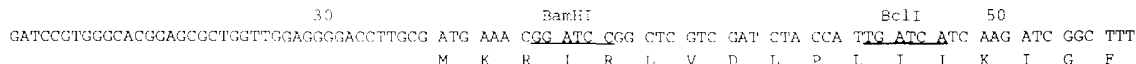

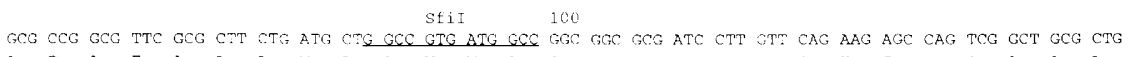

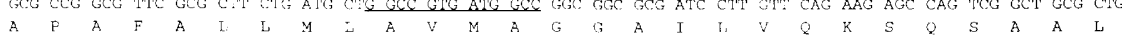
AAG CAG GTC GTG GAA CGC GAC ATG CGT CAG AAT THG GAO ATC CAG CGG ATT TTC AAG CGC ATC TCG AAC ATC AAC GGC GAG

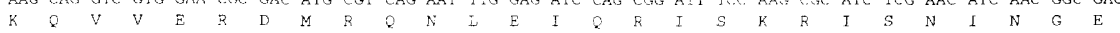
TTG TTC GTC GTC ATG ACT CAT AAG GCT GGC AAT ATC GAC GTC GAC AAG AAC GAC GCG CGT ATC GCC GCC GTT CTG GTC GAG

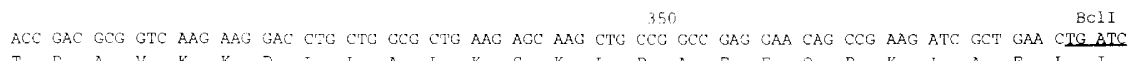

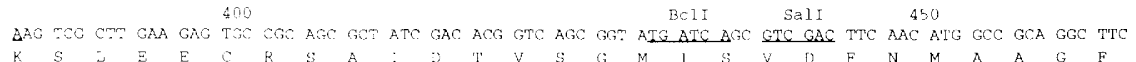

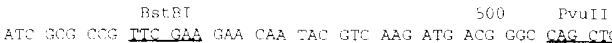

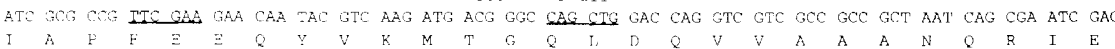

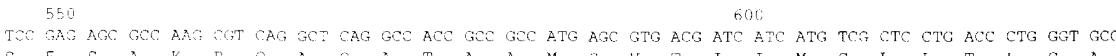
$S$ E $S$ S A

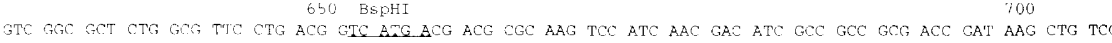

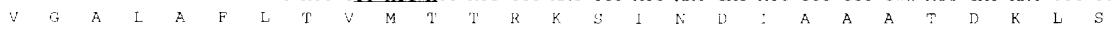

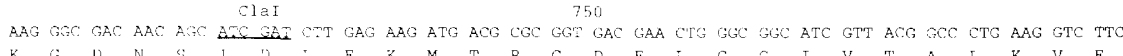

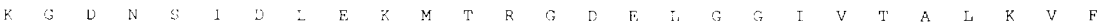

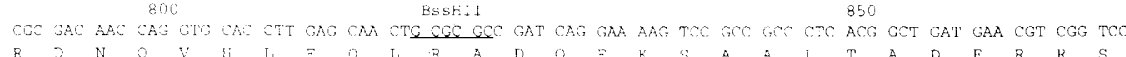

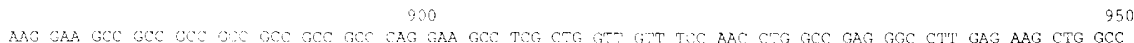

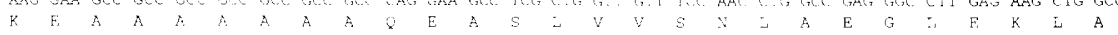

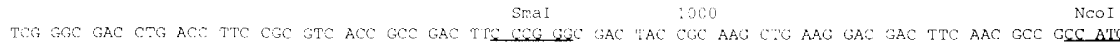

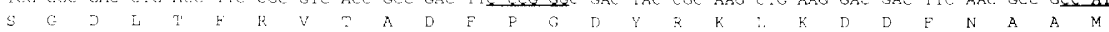

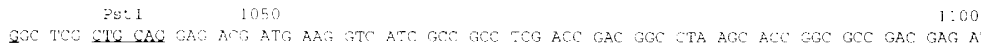

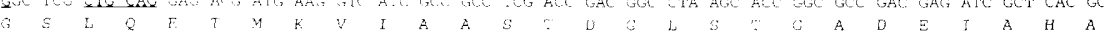

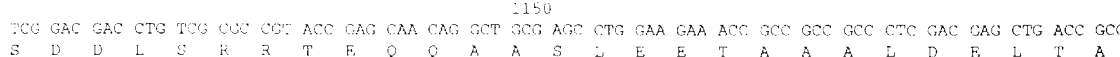
1200 Stul 1250

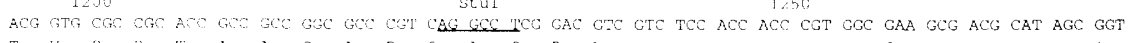
:300 Noo: SACT 1350

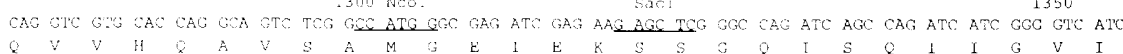
GAC GAA ATC GEC TTO CAO ACE AAC CTT COG GCC CTG AAC GCA GGC GTC GAA GC GCC CGG GCG GGC GAC GCG GGC CGC GGC

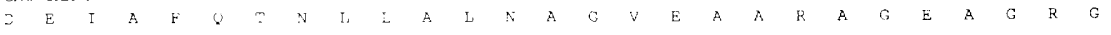

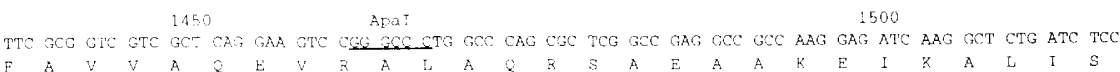

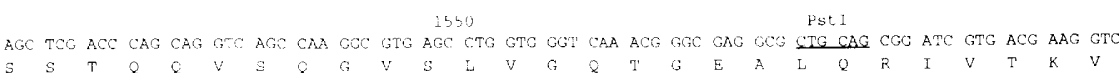
$1600 \quad 1550$

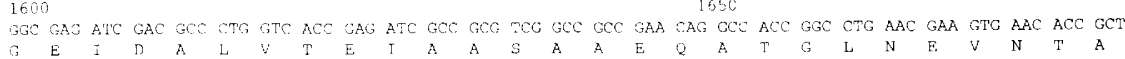

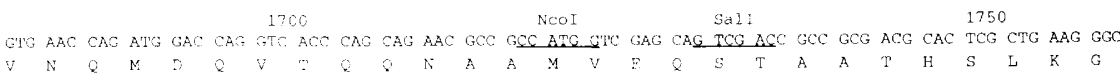

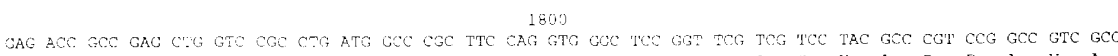

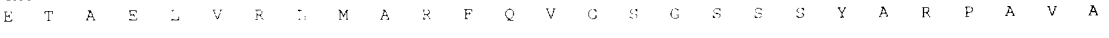

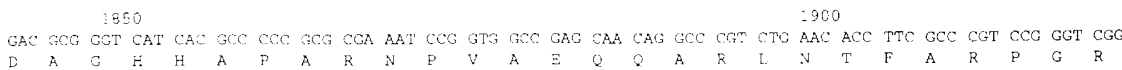
2000

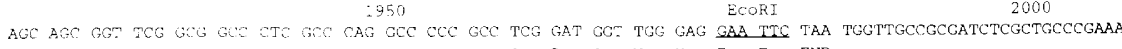
$S$ S G S A A L $D$ A A P A $S$ D B W

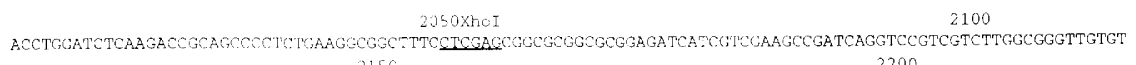
CTGCAAGTGCGTGGCCGCOCGCAAGCCOI 2150 2200 FitoRT 2251

Figure 2. The DNA sequence of the $m c p A$ gene. The predicted amino acid sequence of 657 amino acid residues is denoted by the single-letter amino acid code. The relevant restriction sites are under-

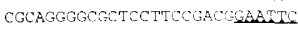




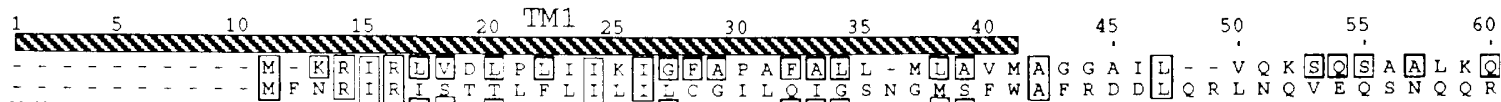

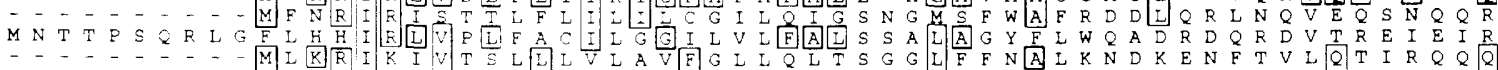

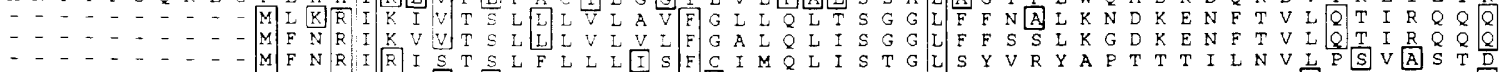

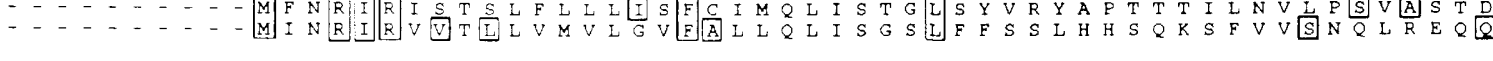
$\begin{array}{llllllllllll}61 & 65 & 70 & 75 & 80 & 85 & 90 & 95 & 100 & 105 & 110 & 115\end{array}$

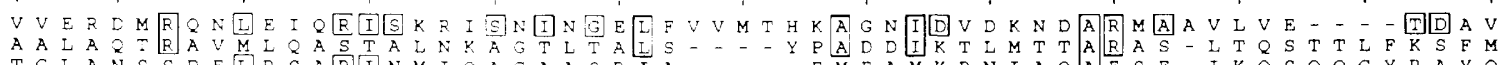

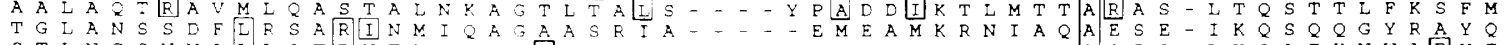

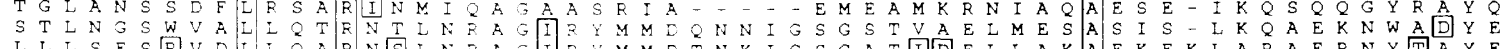

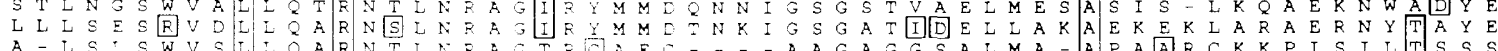

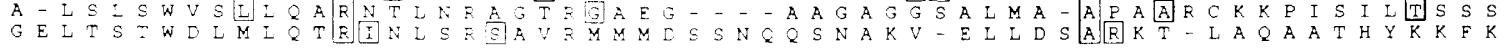
$121 \quad 125$
130
$140 \quad 145$
$250 \quad 155$
160
165
170
$175 \quad 180$

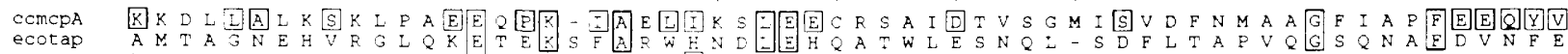

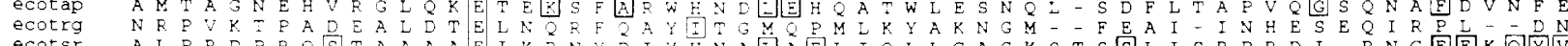

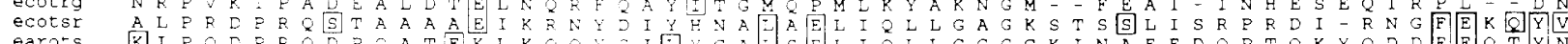

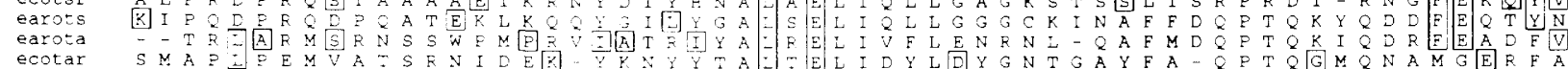
$181 \quad 185 \quad 290 \quad 195$

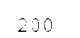

\section{5}

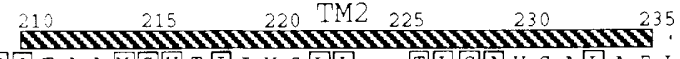

240

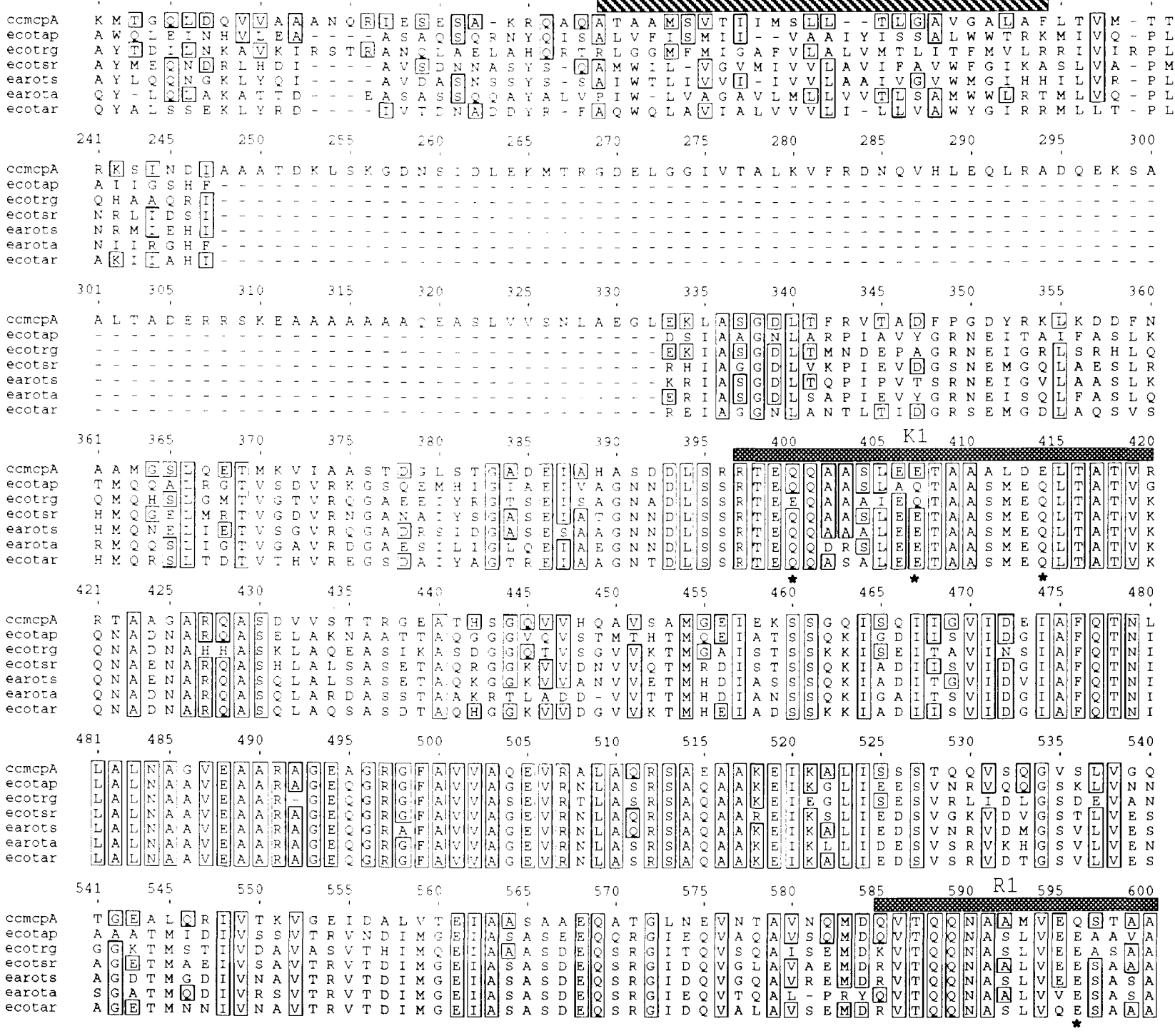

Figure 3. (Continued on facing page.) 

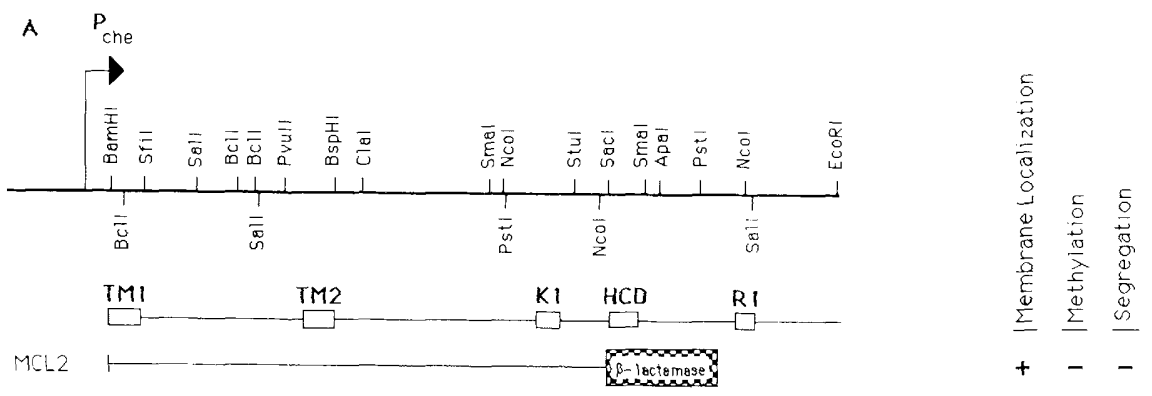

Figure 4. Analysis of progeny segregation, membrane localization, and methylation of the McpA protein and its truncated derivative fused to a $\beta$-lactamase reporter protein. (A) A restriction map of the $m c p A$ gene with the specific regions of the protein denoted below. (TM1) Transmembrane domain 1 ; (TM2) transmembrane domain 2; (K1 and Rl) methylation regions; (HCD) highly conserved domain. (Below) Diagram of the McpA- $\beta$-lactamase protein fusions showing the extent

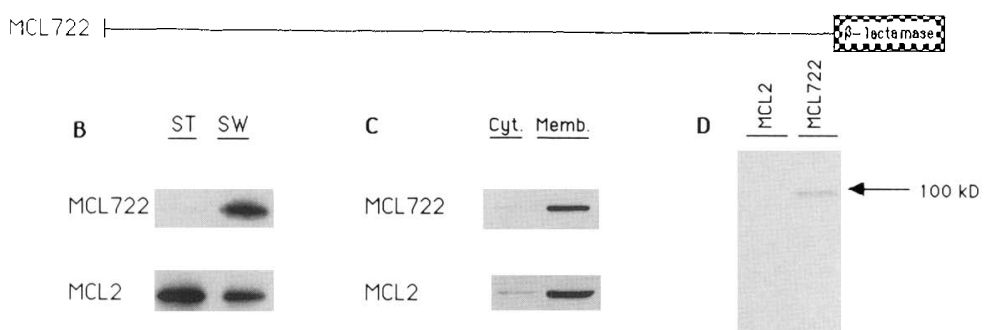
of the McpA protein fused to $\beta$-lactamase. (B) Segregation patterns of the McpA- $\beta$ lactamase fusions. Predivisional cells were pulse labeled at $110 \mathrm{~min}$ into the cell cycle with $\left.{ }^{35} \mathrm{~S}\right]$ methionine and allowed to divide, and the swarmer (SW) and stalked (ST) cell progeny were isolated by centrifugation through a Ludox density gradient, as described in Materials and methods.

The McpA- $\beta$-lactamase protein fusions synthesized in the predivisional cell were immunoprecipitated from each progeny cell type with anti- $\beta$-lactamase antibody. (C) Membrane localization of the McpA- $\beta$-lactamase fusions. Membrane (Memb) and cytosolic (Cyt) fractions of strains MCL722 and MCL2 were prepared as described previously (Shaw et al. 1983) and immunoblotted with anti- $\beta$ lactamase antibody. (D) In vivo methylation of the McpA- $\beta$-lactamase fusions was carried out as described by Gomes and Shapiro (1984). Labeled cultures were lysed and immunoprecipitated with anti- $\beta$-lactamase antibody as described in Materials and methods. The arrow at $100 \mathrm{kD}$ denotes the size of the MCL722 McpA- $\beta$-lactamase fusion.

conclude, therefore, that membrane localization alone is not sufficient for segregation to the swarmer cell.

To address whether methylation might be involved in the segregation process we examined the methylation of these protein fusions (Fig. 4D). The full-length fusion was methylated, but the shorter fusion was not, even though MCL2 retains the $\mathrm{K} 1$ methylation region. Although the loss of McpA segregation correlates with the loss of protein carboxy-methylation, methylation is probably not causal, because a full-length McpA- $\beta$-galactosidase fusion protein is localized to the swarmer pole even in a methylation-minus mutant, $\mathrm{SC1} 130 \mathrm{~N}$ /see
Fig. 8B, below). This strain has a Tn5 insertion in the first gene in the general chemotaxis operon $(m c p A)$ and, owing to the polarity of this insertion, is deficient in methyesterase and methyltransferase activity (Alley et al. 1991; Fig. 1).

\section{Intracellular localization of $M c p A$}

The intracellular localization of McpA was determined by immunoelectron microscopy. Antisera were raised against the g10-McpA fusion protein purified from an overproducing E. coli strain, as described in Materials

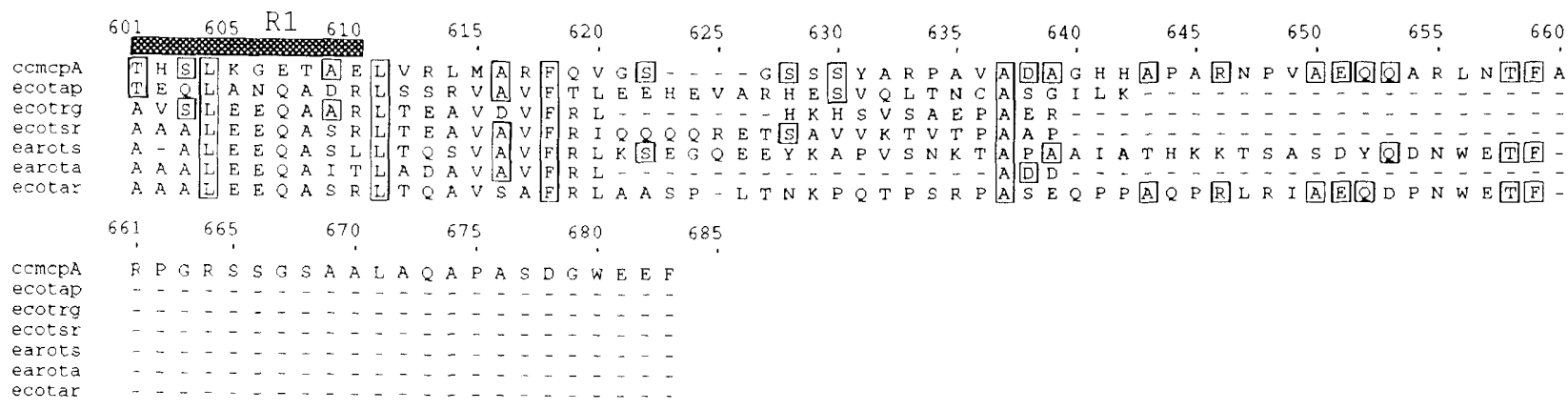

Figure 3. Amino acid sequence comparison of the predicted McpA protein from C. crescentus, four E. coli chemotaxis transducers, and two E. aerogenes transducers. The $C$. crescentus $M c p A$ sequence is indicated as ccmcpA; the $E$. coli sequences, as ecotap (Krikos et al. 1983), ecotrg (Bollinger et al. 1984) with recent corrections (G. Hazelbauer, pers. comm.), ecotsr (Boyd et al. 1983), and ecotar (Krikos et al. 1983); the E. aerogenes sequences, as earots and earota (Dahl et al. 1989). Comparative analysis was performed by the TULLA program (Subbiah and Harrison 1989). The boxed residues denote amino acid identity with the C. crescentus McpA protein. (TM1) transmembrane domain 1; (TM2) transmembrane domain 2; (K1 and R1) methylation regions proposed for the E. coli Tsr chemoreceptor (Kehry et al. 1983). The bold asterisks below the amino acid sequence denote potential methylation sites, on the basis of the reported methylation sites for the E. coli Tsr chemoreceptor (Kehry et al. 1983). The C. crescentus MCP is methylated at glutamate/glutamine residues (Gomes and Shapiro 1984). 
and methods. This antiserum was shown to react with the $70-\mathrm{kD}$ McpA protein in CB15N cell extracts, whereas no $70-\mathrm{kD}$ band was observed in $\mathrm{SC} 1130 \mathrm{~N}$ cell extracts (Fig. 5A). The strain SC1130N carries a Tn5 insertion in the $m c p A$ gene. However, in control experiments, the $70-\mathrm{kD}$ protein band was still observed in SC1062 protein extracts; the strain SC1062 carries a Tn5 insertion in flaE. The antisera also detected a $70-\mathrm{kD}$ protein in $E$. coli $\{\mathrm{KO} 607\rangle$ containing a derivative of the overproducing plasmid pMCP2 (see Table 1).

Swarmer cells were isolated from CB15N wild-type cultures, and the location of McpA was determined by immunoelectron microscopy of fixed and sectioned cells using anti-McpA antibody (Fig. 5B). McpA is localized at the swarmer cell pole of wild-type CB15N, but virtually no signal was present in strain SCl130N (data not shown). In addition to the intense labeling at the flagellated pole, we occasionally observed a small amount of labeling (1-4 gold particles) at the other pole. One interpretation of this result is that both poles of the new swarmer cell are competent for McpA retention. However, the pole bearing the flagellum is the only swarmer pole present when the mcpA gene is expressed in the predivisional cell (Gomes and Shapiro 1984); thus, the flagellated pole would retain the majority of the newly synthesized McpA. Very little chemoreceptor is synthesized following cell division (Gomes and Shapiro 1984), but perhaps a small amount of McpA not localized before cell division can be positioned at either pole after cell division.

To determine the intracellular distribution of the McpA- $\beta$-lactamase fusion (MCL2), which segregates to both daughter progeny, we first determined the positioning of two full-length McpA fusion constructs: McpA$\beta$-galactosidase (CEE281) and McpA- $\beta$-lactamase (MCL722), shown diagrammatically in Figure 6. Using immunoelectron microscopy we found that both the McpA- $\beta$-galactosidase fusion (Fig. 7A,B) and the McpA$\beta$-lactamase fusion protein (Fig. 7C,D) appear predominantly at the flagellated pole of the swarmer cell. Thus, like the native McpA protein, both $\beta$-galactosidase and $\beta$-lactamase fusions to the full-length $\mathrm{McpA}$ protein were localized to the cell pole. The intracellular positioning of the shorter McpA- $\beta$-lactamase fusion (MCL2) was then examined (Fig. 6). This protein fusion lacks the carboxyl one-third of the McpA protein and is still membrane localized. However, unlike the full-length fusion protein, it is distributed evenly around the swarmer cell (Fig. 7E,F), implicating the carboxy-terminal portion of the protein in segregation to the swarmer cell and in polar localization of the protein.

To determine whether carboxy-methylation of McpA is required for polar localization, we examined the positioning of a full-length McpA- $\beta$-galactosidase fusion protein encoded by $m c p A-l a c Z$ carried on a plasmid (pRCHZ10) in the carboxy-methylation-minus mutant $\mathrm{SC} 1130 \mathrm{~N}$. Because this plasmid-borne fusion is present at two to three copies per cell, we first ascertained whether the plasmid-borne McpA- $\beta$-galactosidase fusion protein is localized polarly in the $C$. crescentus wild-type strain $\mathrm{CB} 15 \mathrm{~N}$. As expected, the McpA- $\beta$-galactosidase fusion protein was positioned predominantly at the flagellated pole of $\mathrm{CB} 15 \mathrm{~N}$ swarmer cells (Fig. 8A). Thus, both chromosomal and plasmid-encoded McpA

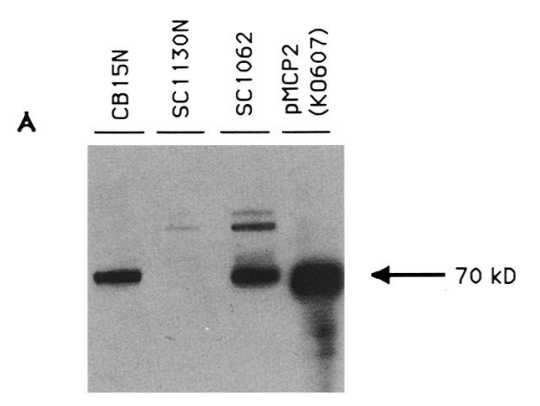

Figure 5. Polar localization of the C. crescentus McpA chemoreceptor by immunoelectron microscopy. (A) Immunoblots (Towbin et al. 1979) of $C$. crescentus cell extracts of wild-type C. crescentus CB15N, mutant strains SC1130N and SC1062, and an $E$. coli strain $\mathrm{KO} 607$, carrying the plasmid-borne McpA gene (pMCP2) using antisera raised against $\mathrm{T} 7 \mathrm{~g} 10-\mathrm{McpA}$, as described in Materials and methods. (B) Electron micrographs of fixed and sectioned wild-type swarmer cells treated with a 1/800 dilution of anti-McpA antibody, and visualized by using goat anti-rabbit $10 \mathrm{nM}$ colloidal gold conjugates as the secondary antibody. Bar, $0.5 \mu \mathrm{M}$.
B

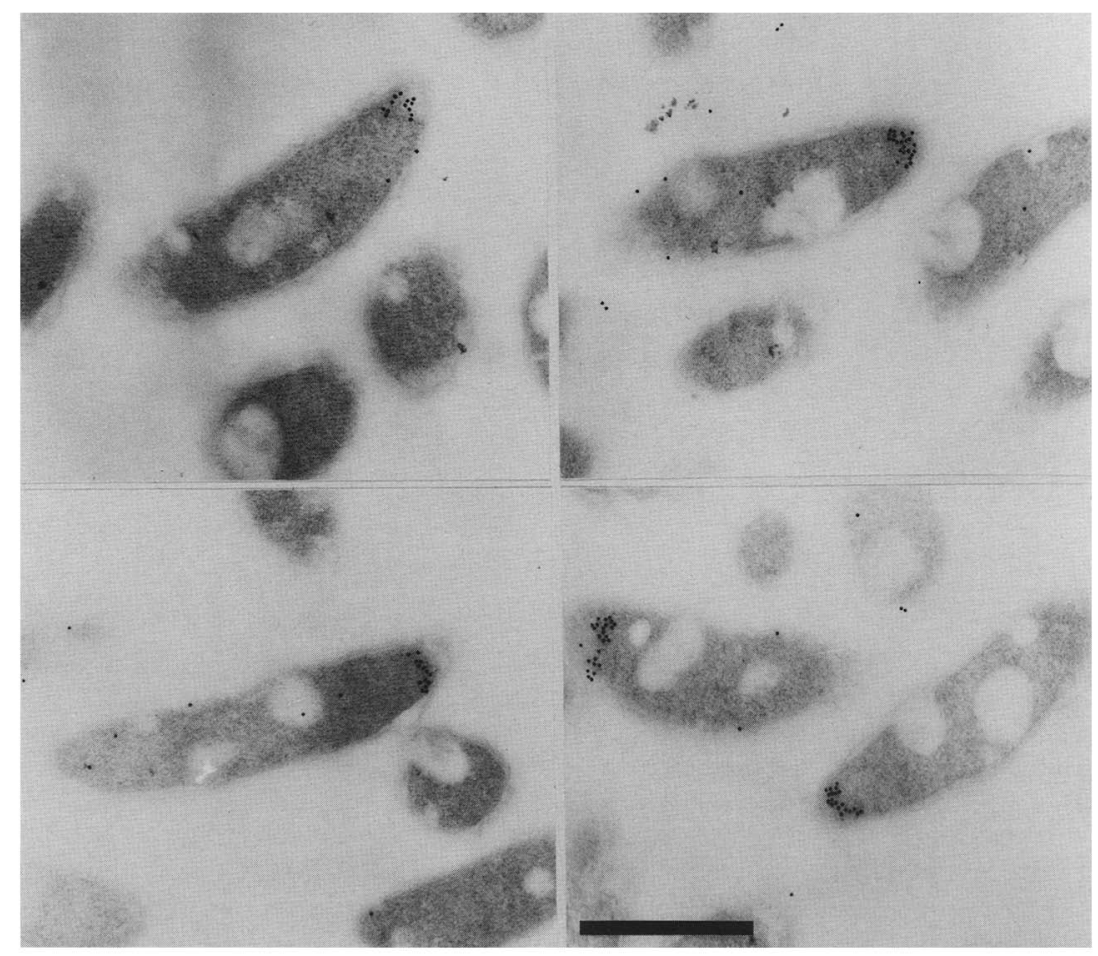


Table 1. Bacterial strains and plasmids

\begin{tabular}{|c|c|c|c|}
\hline \multicolumn{2}{|c|}{ Bacterial strains } & Genotype or description & Reference \\
\hline E. coli & $\begin{array}{l}\text { K0607 } \\
\text { S17-1 } \\
\text { MG1655 }\end{array}$ & $\begin{array}{l}\Delta t s r-7021, \Delta(\text { tar-tap) 5201, } \Delta \text { trg-100, recA56 } \\
\text { M294::RP4,2-Tc::Mu, Km::Tn7 } \\
\text { F } \lambda^{-}\end{array}$ & $\begin{array}{l}\text { Oosawa et al. }(1988) \\
\text { Simon et al. }(1983) \\
\text { Guyer et al. }(1980)\end{array}$ \\
\hline C. crescentus & $\begin{array}{l}\text { CB15N } \\
\text { SC1130N } \\
\text { SC1062 } \\
\text { SU203 (MCL722) } \\
\text { SU204 (MCL2) } \\
\text { SU205 (CEE281) }\end{array}$ & $\begin{array}{l}\text { synchronizable wild type } \\
\text { synchronizable derivative of SC1 } 130 \mathrm{mcp} A: \operatorname{Tn} 5 \text {; } \\
\text { methylesterase and methyltransferase deficient } \\
\text { flaE178::Tn5 ProA Str-104 } \\
\text { CB15N::pMCL722 } \\
\text { CB15N::pMCL2 } \\
\text { CB15N::pCEE281 }\end{array}$ & $\begin{array}{l}\text { Evinger and Agabian (1977) } \\
\text { Alley et al. (1991) } \\
\text { Purucker et al. (1982) } \\
\text { this study } \\
\text { this study } \\
\text { Alley et al. (1991) }\end{array}$ \\
\hline Plasmids & $\begin{array}{l}\text { pMCL722 } \\
\text { pMCL2 } \\
\text { pJBZ281 } \\
\text { pCEE281 } \\
\text { pRK290 } \\
\text { pRCHZ10 } \\
\text { pLVC9 } \\
\text { pRTSR 1 }\end{array}$ & 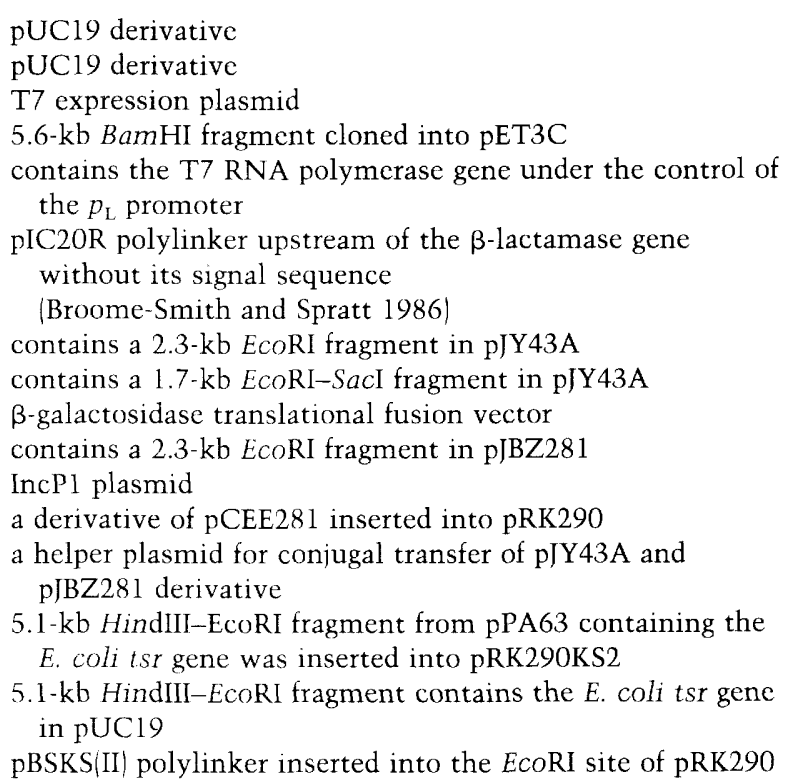 & $\begin{array}{l}\text { this study } \\
\text { this study } \\
\text { Alley et al. (1991) } \\
\text { Alley et al. (1991) } \\
\text { Ditta et al. (1980) } \\
\text { this study } \\
\text { G. Warren (unpubl.) } \\
\text { this study }\end{array}$ \\
\hline
\end{tabular}

protein fusions are localized to the cell pole, suggesting that polar sites are not saturated in the CB15N/ pRCHZ10 strain. As shown in Figure 8B, the fusion protein is localized to the cell pole in strain SC1130N. Strain SC1130N lacks the enzymes to carry out carboxymethylation (Alley et al. 1991), and thus localization does not depend upon the carboxy-methylation of the McpA moiety.

\section{Asymmetric segregation of the E.coli chemoreceptor Tsr expressed in C. crescentus}

The amino acid sequence of the carboxy-terminal portions of the $C$. crescentus McpA and the E. coli Tsr chemotaxis transducer is highly conserved. Because we have shown that this region of $\mathrm{McpA}$ is required for swarmer cell segregation and for polar localization, we determined the fate of the E. coli tsr gene product when it is expressed in C. crescentus. We chose the Tsr chemoreceptor because we had demonstrated previously that $t s r$ is transcribed in $C$. crescentus from its native start site in a cell cycle pattern similar to the endogenous C. crescentus chemoreceptor /Frederikse and Shapiro 1989|. We generated a strain of C. crescentus that carries a plasmid-borne E. coli tsr gene (pRTSR1) and asked whether the Tsr protein specifically segregates to the progeny swarmer cell. The newly synthesized Tsr protein, labeled in the predivisional cell, segregates predominantly to the swarmer cell (Fig. 9). Therefore, E. coli Tsr contains all of the information necessary for swarmer cell-specific segregation.

\section{Discussion}

We have determined that the chemoreceptor McpA is spatially constrained to the pole of the $C$. crescentus swarmer cell. The cell pole that bears the flagellum, and to which the chemotaxis MCPs are localized, is the division site of the previous cell division. It is possible that epigenetic information is passed on at the cell poles by the deposition of specific proteins at the division plane. Huguenel and Newton (1982) have reported that cell division events in the previous cell cycle are required for the assembly of structures at the cell pole. Both membrane flagellin pools (Huguenel and Newton 1984) and MCPs (Nathan et al. 1986) are preferentially associated with membrane vesicles prepared from the cell poles, suggesting that $C$. crescentus has unique polar domains. 


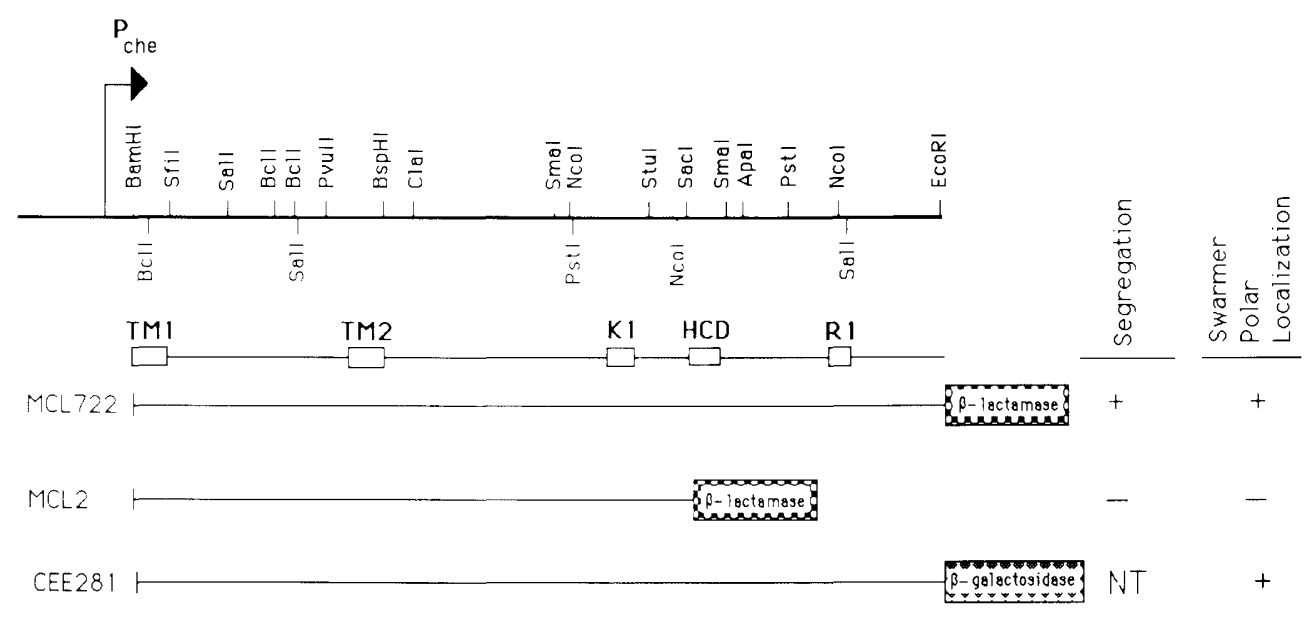

Figure 6. A restriction map of the mcpA gene with the specific regions of the protein denoted below, as described in the legend to Fig. 4. (Below) Diagram of McpA protein fusions to $\beta$-lactamase or to $\beta$-galactosidase, accompanied by a summary of the segregation data presented in Fig. 4 B and the immunoelectron microscopy localization data shown in Fig. 7. (NT) Not tested.

There are at least two mechanisms by which polar localization of McpA could occur. First, McpA could be inserted randomly in the inner membrane and could reach the cell pole by diffusion. Once it has reached the cell pole, it could be constrained. Retention of McpA at the pole could be the result of interactions with one or more polar proteins or by a physical barrier that allows McpA to enter, but not exit, the pole. Our second model predicts that McpA is inserted only at the pole of the cell via a specific localized secretory pathway. This model also requires McpA retention at the pole, either by interactions with polar proteins or by a physical barrier. Evidence for such a barrier, the polar periseptal annulus, has been reported for E. coli (Cook et al. 1986).

A chemoreceptor lacking the native carboxy-terminal region is inserted in the membrane but is not localized to the cell pole. How can these models account for the random cellular distribution of the McpA with a deleted carboxyl terminus? Both models require that McpA is sequestered at the polc. Therefore, the deleted region is responsible, in part, for specific protein interactions and/ or retention by a physical barrier. The second model demands that the choice of secretory pathway is determined by domains in the carboxyl terminus. The random membrane insertion of the deleted protein would then, in effect, occur by a default pathway, perhaps by using the $\sec A$-dependent membrane insertion pathway of the E. coli Tsr protein (Gebert et al. 1988', which requires an amino-terminal signal sequence. A carboxyterminal signal has been shown to be sufficient for membrane targeting and translocation of the E. coli hemolysin protein (HylA) (Koronakis et al. 1989).

Because our experiments suggest that sequences within the carboxyl terminus of McpA are responsible for specific polar localization, we compared McpA sequences with those of the other chemoreceptors (Fig. 3). Within this region are the methylation domains as well as the HCD. Both methylation regions $\mathrm{R} 1$ and $\mathrm{K} 1$ are conserved but not to the same extent as the HCD. Two proteins interact with the $\mathrm{R} l$ and $\mathrm{K} l$ regions, the methylesterase and the methyltransferase, involved in removing and adding methyl groups to glutamic acid residues at certain sites in the $\mathrm{R} 1$ and $\mathrm{Kl}$ regions. The truncated McpA- $\beta$-lactamase fusion is not methylated, although it retains an intact $\mathrm{K} 1$ methylation region. A similar finding was reported using a truncated Tar protein that had the $\mathrm{R} 1$ region deleted (Krikos et al. 1985). Although there is a correlation between the absence of methylation and the inability of the truncated McpA- $\beta$-lactamase fusion to be polarly localized in swarmer cells, we found using a methylation-deficient mutant, SC1130N, that methylation of McpA is not required for polar localization. The transposon insertion in this mutant strain is polar, and therefore other chemotaxis proteins present in this operon (Alley et al. 1991), such as cheA, cheW, methylesterase, and methyltransferase, are not required for polar localization of McpA.

The most striking feature of the chemoreceptor amino acid sequence comparison is the near identity of the cytoplasmic HCD in enterics and the phylogenetically distant $C$. crescentus. This suggests a strong selective pressure to maintain this region, perhaps owing to a number of protein interactions with this domain. It has been inferred from genetic data that cheA (J.S. Parkinson, pers. comm.) and cheW (Liu and Parkinson 1991) interact with the chemoreceptor at the highly conserved domain. The sequence similarity between $E$. coli and $C$. crescentus chemotaxis proteins may be sufficient for these proteins to be functionally equivalent. We have found that when the E. coli chemoreceptor Tsr is expressed in C. crescentus, it segregates to the swarmer cell. Sequences in the HCD might interact with a complex of proteins at the cell pole, as well as with the cytoplasmic CheW and CheA proteins involved in chemotaxis signal transduction.

C. crescentus utilizes a number of mechanisms to position cell type-specific proteins to the correct cell progeny, as well as to the correct region of the cell. Some 

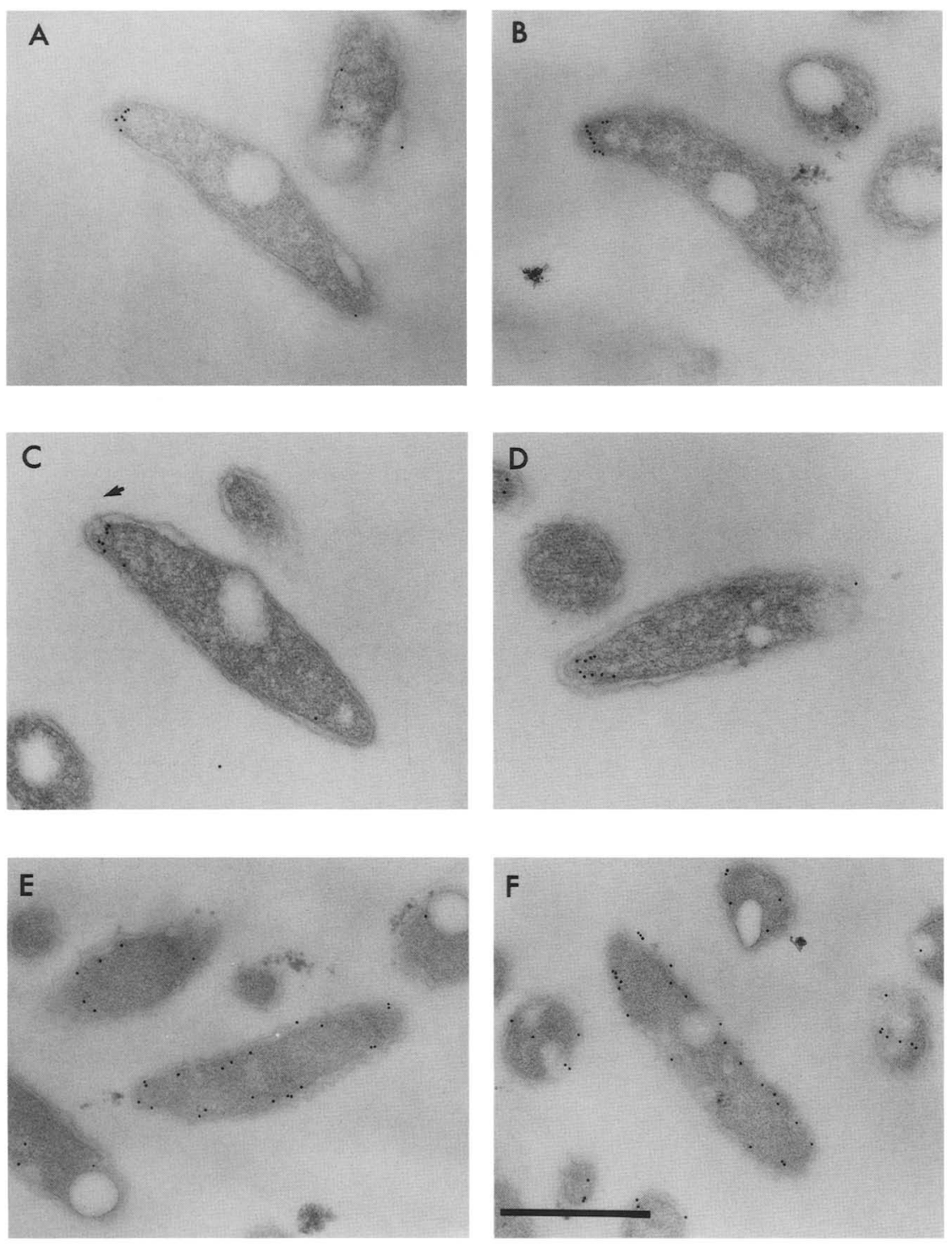

Figure 7. Localization of McpA fusion proteins within $C$. crescentus swarmer cells by immunoelectron microscopy. $(A, B)$ Wild-type CB15N swarmer cells containing a chromosomal full-length McpA- $\beta$-galactosidase fusion (CEE281); the sectioned cells are treated with anti$\beta$-galactosidase antibody, as the primary antibody. $(C, D)$ A full-length McpA- $\beta$ lactamase fusion (MCL722). $(E, F)$ A truncated McpA- $\beta$-lactamase fusion (MCL2) treated with anti- $\beta$-lactamase antibody as the primary antibody. The positions of these fusion proteins are visualized by 10 nM colloidal gold spots conjugated to goat anti-rabbit antibody. The arrow in $C$ identifies a rare cross section through a flagellum. Bar, $0.5 \mu \mathrm{M}$. proteins are positioned owing to cell type-specific transcription (Gober et al. 1991b). Other proteins, such as pilins, are dispersed throughout the predivisional cell and are assembled only at the swarmer pole (Smit 1987). In this report we have demonstrated polar positioning of the newly synthesized chemoreceptor McpA, which is dependent on sequences in the carboxy-terminal domain of the protein. McpA is still localized polarly in mutants that fail to assemble polar structures such as pili and flagella, and in mutants that have a paralyzed flagellum (J. Maddock, unpubl.). We do not know whether McpA is positioned at the pole of the swarmer cell because of a functional relationship with the flagellar motor or whether the polar positioning reflects a general mechanism used by prokaryotes to localize specific categories of proteins. Expcriments by Engström and Hazclbauer (1982) suggest that the MCPs are not tightly associated with the basal bodies of the peritrichous flagella in $E$. coli, thus arguing against a spatial requirement for func- tional interaction. The high degree of sequence similarity and functional equivalency between the C. crescentus and $E$. coli chemotaxis receptor proteins leads us to speculate that the E. coli MCPs may be associated with the poles of the cell as they are in C. crescentus.

\section{Materials and methods}

Bacterial strains, plasmids, and growth conditions

The bacterial strains and plasmids used in this study are listed in Table 1. C. crescentus was grown at $32^{\circ} \mathrm{C}$ in either PYE (Poindexter 1964) or minimal M2 medium (Johnson and Ely 1977). Plasmids were transferred from E. coli to C. crescentus by conjugal transfer as described by Alley et al. (1991).

\section{Immunoprecipitation assays of synchronized cells}

Swarmer cells were collected from Ludox density gradients, as described by Evinger and Agabian (1977). The swarmer cells 
Figure 8. Subcellular localization of McpA in wild-type and chromotaxis methylation mutants. The distribution of the fusion protein encoded by the fulllength McpA gene fused to lac $Z$ on plasmid pRCHZ10 was monitored in swarmer cells from wild-type C. crescentus $\mathrm{CB} 15 \mathrm{~N}|A|$ and in the che strain SC1130N $(B)$. The McpA- $\beta$-galactosidase fusion was stained with anti- $\beta$-galactosidase antibody and visualized by colloidal gold conjugated to goat anti-rabbit antibody. Bar, $0.5 \mu \mathrm{M}$.

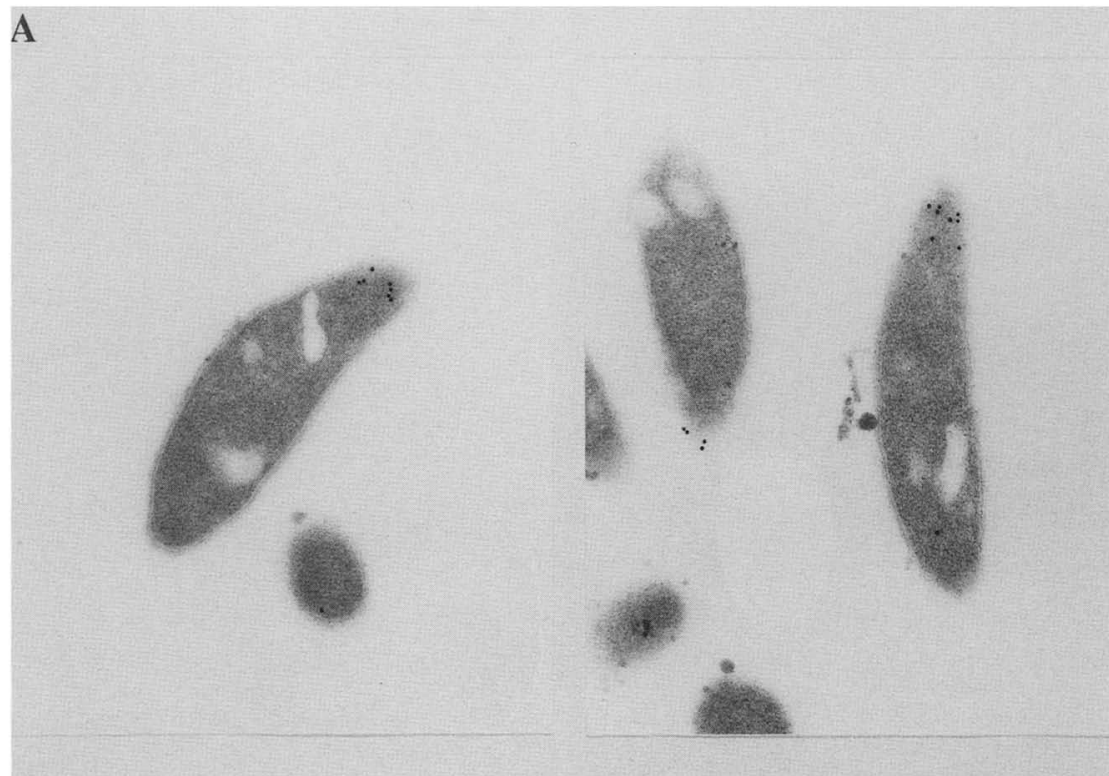

B

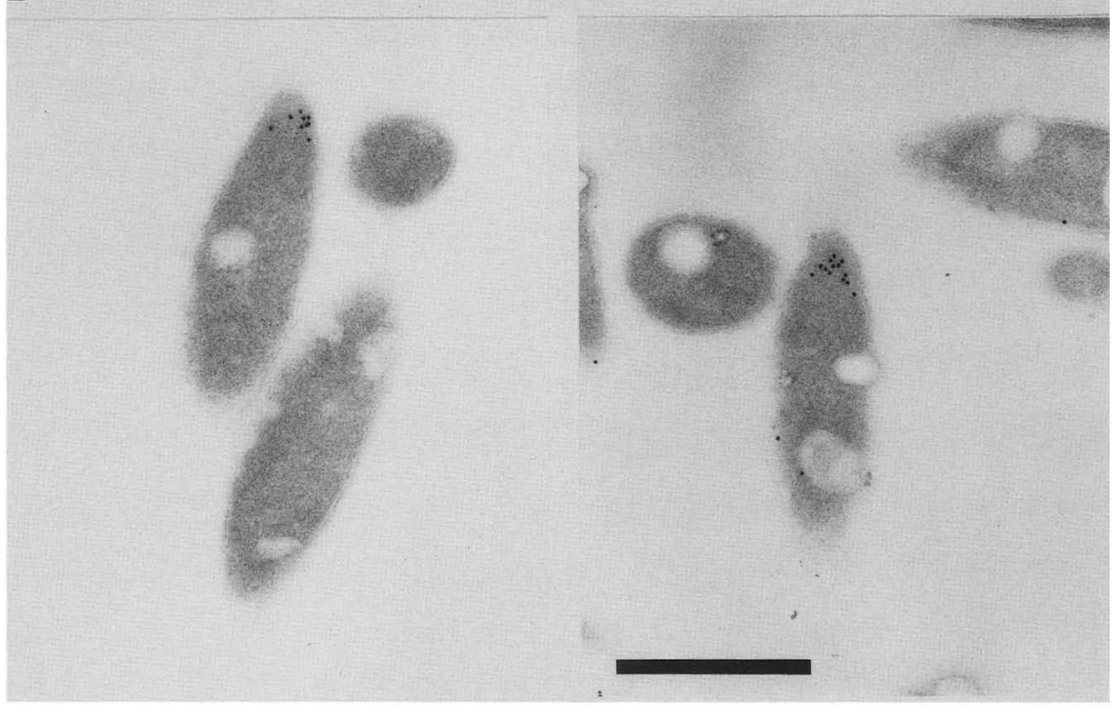

were allowed to proceed synchronously through the cell cycle in fresh media, and at $110 \mathrm{~min}$ (of a $180 \mathrm{~min}$ generation time) predivisional cells were incubated with $\left[{ }^{35} \mathrm{~S} \mid\right.$ methionine $3 \mu \mathrm{Ci} /$ $\mathrm{ml}$ ) for $10 \mathrm{~min}$, chased with $2 \mathrm{~mm}$ methionine and $0.2 \%(\mathrm{wt} / \mathrm{vol} \mid$ Bacto-peptone, and allowed to divide. The progeny swarmer and stalked cells were separated by Ludox density centrifugation. Cell extracts were prepared and immunoprecipitated with anti$\beta$-lactamase antibody, as described previously (Gomes and Shapiro 1984). Proteins were separated by electrophoresis through $10 \%(\mathrm{wt} / \mathrm{vol}$ ) (SDS-PAGE). Labeled proteins were detected by autoradiography.

\section{DNA sequencing strategy}

The 2.3-kb EcoRI fragment was cloned into pBS $|\mathrm{II}| \mathrm{KS}|+|$ in both directions, and deletions were created by exonuclease III and SI nuclease digestion (Pharmacia nested deletion kit) to create nested deletions in both directions. These deletions were sequenced using double-stranded templates in Sanger dideoxynu- cleotide sequencing reactions (Sanger et al. 1977) with Sequenase (U.S. Biochemical) and 7-deaza-dGTP. DNA sequences that had ambiguous $\mathrm{GC}$ compressions were subcloned into $\mathrm{Ml} 3$ mp 18/mp 19 (Norrander et al. 1983) and sequenced using dITP. The adjoining 280-bp EcoRI fragment was cloned into M13, mpl8, and $\mathrm{mpl} 19$ and sequenced in both directions.

Purification of the C. crescentus $M c p A$ protein and generation of anti-McpA antibody

McpA was overexpressed in E. coli (MG1655) using a T7 expression system (Tabor and Richardson 1985). The 5.6-kb BamHI fragment shown in Figure 1 was inserted into pET3C to create pMCP1, a translational fusion between $\mathrm{g} 10$ (T7 capsid protein and $m c p A$ under the control of a T7 promoter. The plasmid pMCPl was then introduced into the $E$. coli strain MGl655 bearing the T7 RNA polymerase gene, pG1-2. Overexpression of the fusion protein was performed as described by Tabor and Richardson (1985). Isolation of membranes from the disrupted 


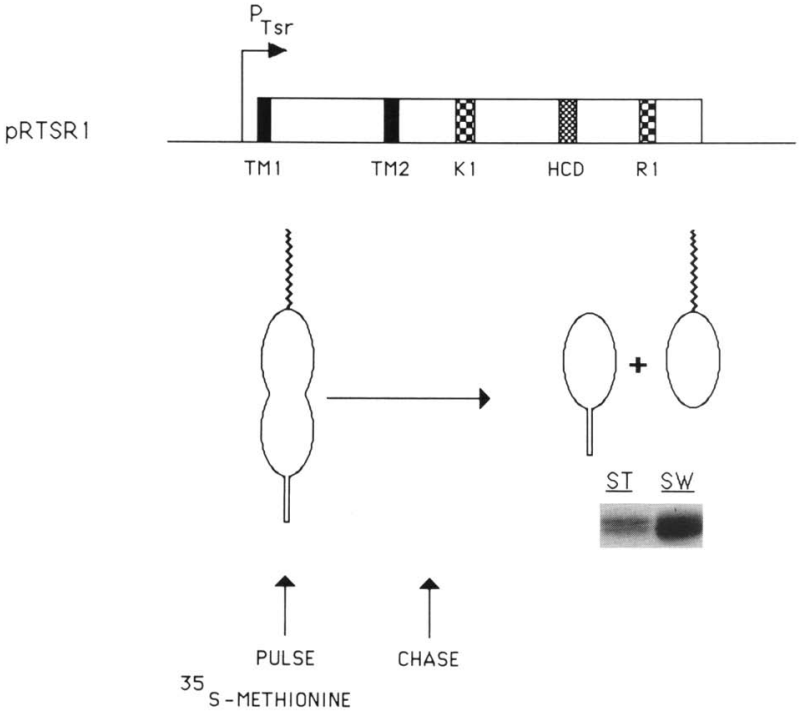

Figure 9. Progeny cell segregation of the E.coli Tsr chemoreceptor expressed in C. crescentus. Predivisional cells of C. crescentus bearing a plasmid containing the E. coli tsr gene (pRTSR1) were pulse labeled with $\left[{ }^{35} \mathrm{~S}\right]$ methionine. The label was chased with cold methionine, and swarmer and stalked cell progeny were separated following cell division, as described in Materials and methods. Labeled proteins were immunoprecipitated from stalked (ST) and swarmer (SW) cells using anti-Tar antiserum. As a control, immunoprecipitation was also performed using flagellin antiserum (data not shown).

cells was performed as described by Burrows et al. (1989). The isolated membranes were subjected to SDS-PAGE and the fusion protein was then visualized using $(0.05 \% \mathrm{wt} / \mathrm{vol})$ Coomassie brilliant blue in water. The corresponding protein band was excised and used to immunize a rabbit, performed by Josman Laboratories (Napa, CA).

\section{Immunoelectron microscopy}

Swarmer cells were collected and fixed in cold 3\% formaldehyde, $0.1 \%$ glutaraldehyde, in $20 \mathrm{~mm}$ phosphate buffer for $1-2$ hr on ice. Dehydration, infiltration, polymerization of LR White resin, preparation of "sticky" grids, and antibody reactions are described in Wright and Rine 1989. A $1: 500$ dilution, in PBST (140 mM NaCl, $30 \mathrm{~mm} \mathrm{KCl}, 8 \mathrm{~mm} \mathrm{NA} \mathrm{HPO}_{4}, 1.5 \mathrm{~mm} \mathrm{KH}_{2} \mathrm{PO}_{4}$, and $0.05 \%$ Tween-20) plus $2 \%$ BSA of primary antibody was typically used. The secondary antibody was a $1: 30$ dilution of goat anti-rabbit $10 \mathrm{~nm}$ colloidal gold conjugates (Jackson ImmunoResearch, West Grove, PA) in PBST plus 2\% BSA. The background signal that we observed under these conditions using either anti- $\beta$-lactamase or anti- $\beta$-galactosidase antibodies was $0-3$ gold particles/cell. The anti-McpA antibody had virtually no cross-reactivity with SC1130N (0-2 gold particles/cell). Secondary antibody only resulted in $0-1$ gold particles/cell. Sections were poststained with saturated uranyl acetate (in 50\% ETOH) and examined at $60 \mathrm{kV}$ on a Phillips 300 electron microscope.

\section{Acknowledgments}

This investigation was supported by U.S. Public Health Service grant GM32506 from the National Institutes of Health (NIH).
J.R.M. is an NIH postdoctoral fellow. We thank Dan Koshland for the anti-Tar antisera and Bob Bourret for his generous gifts of E. coli strains, plasmids, and antibodies.

The publication costs of this article were defrayed in part by payment of page charges. This article must therefore be hereby marked "advertisement" in accordance with 18 USC section 1734 solely to indicate this fact.

\section{References}

Alley, M.R.K., S.L. Gomes, W. Alexander, and L. Shapiro. 1991. Genetic analysis of a temporally transcribed chemotaxis gene cluster in Caulobacter crescentus. Genetics 129: 333342.

Bollinger, J., C. Park, S. Harayama, and G.L. Hazelbauer. 1984. Structure of the Trg protein: Homologies with and differences from other sensory transducers of Escherichia coli. Proc. Natl. Acad. Sci. 81: 3287--3291.

Boyd, A., K. Kendall, and M.I. Simon. 1983. Structure of the serine chemoreceptor in Escherichia coli. Nature 301: 623626.

Broome-Smith, J.K. and B.G. Spratt. 1986. A vector for the construction of translational fusions to TEM $\beta$-lactamase and the analysis of protein signals and membrane protein topology. Gene 49: 341-349.

Burrows, G.G., M.E. Newcomer, and G.L. Hazelbauer. 1989. Purification of receptor protein Trg by exploiting a property common to chemotactic transducers of E. coli. J. Biol. Chem. 264: 17309-17315.

Cook, W.R., T.J. MacAlister, and L.I. Rothfield. 1986. Compartmentalization of the periplasmic space at division sites in gram negative bacteria. J. Bacteriol. 168: 1430-1438.

Dahl, M.K., W. Boos, and M.D. Manson. 1989. Evolution of chemotactic-signal transducer in enteric bacteria. $/$. Bacteriol. 171: 2361-2371.

Devereux, D., P. Haeberli, and O. Smithies. 1984. A comprehensive set of sequence analysis program for the Vax. $\mathrm{Nu}$ cleic Acids Res. 12: 387-395.

Ditta, G., D. Stanfield, D. Corbin, and D.R. Helinski. 1980. Broad host range cloning system for gram-negative bacteria: Construction of a gene bank for Rhizobium meliloti. Proc. Natl. Acad. Sci. 77: 7347-7351.

Engström, P. and G.L. Hazelbauer. 1982. Methyl-accepting chemotaxis proteins are distributed in the membrane independently from basal ends of the bacterial flagella. Biochim. Biophys. Acta 686: 19-26.

Evinger, M. and N. Agabian. 1977. Envelope-associated nucleoid from Caulobacter crescentus stalked and swarmer cells. I. Bacteriol. 132: 294-301.

Frederikse, P. and L. Shapiro. 1989. An Escherichia coli chemoreceptor gene is temporally controlled in Caulobacter. Proc. Natl. Acad. Sci. 86: 4061-4065.

Gebert, J.F., B. Overhoff, M.D. Manson, and W. Boos. 1988. The Tsr chemosensory transducer of Escherichia coli assembles into cytoplasmic membrane via a SecA-dependent process. J. Biol. Chem. 263: 16652-16660.

Gober, J.W., M.R.K. Alley, and L. Shapiro. 1991a. Positional information during Caulobacter cell differentiation. Curr. Opin. Genet. Dev. 1: 324-329.

Gober, J. W., R. Champer, S. Reuter, and L. Shapiro. 1991b. Expression of positional information during cell differentiation in Caulobacter. Cell 64: 381-391.

Gomes, S.L. and L. Shapiro. 1984. Differential expression and positioning of chemotaxis methylation proteins in Caulobacter. J. Mol. Biol. 177: 551-568. 
Guyer, M.S., R.R. Reed, J.A. Steitz, and K.B. Low. 1980. Identification of a sex-factor-affinity site in $E$. coli as $\gamma \delta$. Cold Spring Harbor Symp. Quant. Biol. 45: 135-140.

Huguenel, E.D. and A. Newton 1982. Localization of surface structures during prokaryotic differentiation: Role of cell division in Caulobacter crescentus. Differentiation 21: 71-78.

. 1984. Isolation of flagellated membrane vesicles from Caulobacter crescentus cells: Evidence for functional differentiation of polar membrane domains. Proc. Natl. Acad. Sci. 81: 3409-3413.

Johnson, R.C. and B. Ely. 1977. Isolation of spontancously derived mutants of Caulobacter crescentus. Genetics 86: 2532.

Kehry, M.R., M.W. Bond, M.W. Hunkapiller, and F.W. Dahlquist. 1983. Enzymatic deamidation of methyl-accepting chemotaxis proteins in Escherichia coli catalysed by the cheB gene product. Proc. Natl. Acad. Sci. 80: 3599-3603.

Koronakis, V., E. Koronakis, and C. Hughes. 1989. Isolation and analysis of the C-terminal signal directing export of Escherichia coli hemolysin protein across both bacterial membranes. EMBO J. 8: 595-605.

Krikos, A., N. Mutoh, A. Boyd, and M.I. Simon. 1983. Sensory transducers of E.coli are composed of discrete structural and functional domains. Cell 33: 615-622.

Krikos, A., M.P. Conley, A. Boyd, H.C. Berg, and M.I. Simon. 1985. Chimeric chemosensory transducers of Escherichia coli. Proc. Natl. Acad. Sci. 82: 1326-1330.

Liu, J. and J.S. Parkinson. 1991. Genetic evidence for interaction between the CheW and Tsr proteins during chemoreceptor signaling by Escherichia coli. I. Bacteriol. 173: 4941-4951.

Loewy, Z.G., R.A. Bryan, S.H. Reuter, and L. Shapiro. 1987. Control of synthesis and positioning of a Caulobacter crescentus flagellar protein. Genes \& Dev. 1: 626-635.

Marsh, J.L., M. Erfle, and E.J. Wykes. 1984. The pIC plasmid and phage vectors with versatile cloning sites for recombinant selection by insertional inactivation. Gene 32: 481-485.

Milhausen, M. and N. Agabian. 1983. Caulobacter flagellin mRNA segregates asymmetrically at cell division. Nature 328: $80-82$.

Nathan, P., S.L. Gomes, K. Hahnenberger, A. Newton, and L. Shapiro. 1986. Differential localization of membrane receptor chemotaxis proteins in the Caulobacter predivisional cell. I. Mol. Biol. 191: 433-440.

Norrander, J., T. Kempe, and J. Messing. 1983. Construction of improved M13 vectors using oligodeoxynucleotide-directed mutagenesis. Gene 26: 101-106.

Oosawa, K., N. Mutoh, and M.I. Simon. 1988. Cloning of the C-terminal cytoplasmic fragment of the Tar protein and effects of the fragment on chemotaxis of Escherichia coli. I. Bacteriol. 170: 2521-2526.

Poindexter, J.S. 1964. Biological properties and classification of the Caulobacter group. Bacteriol. Rev. 28: 231-295.

Punucker, M., R. Bryan, K. Amemiya, B. Ely, and L. Shapiro. 1982. Isolation of a Caulobacter gene cluster specifying flagellum production by using nonmotile Tn 5 insertion mutants. Proc. Natl. Acad. Sci. 79: 6797-6801.

Reuter, S.H. and L. Shapiro. 1987. Asymmetric segregation of heat-shock proteins upon cell division in Caulobacter crescentus. J. Mol. Biol. 194: 653-662.

Sanger, F., S. Nicklen, and A.R. Coulson. 1977. DNA sequencing with chain-terminating inhibitors. Proc. Natl. Acad. Sci. 74: 5463-5467.

Shaw, P., S.L. Gomes, K. Sweeny, B. Ely, and L. Shapiro. 1983. Methylation involved in chemotaxis is regulated during Caulobacter differentiation. Proc. Nat1. Acad. Sci. 80: 52615265.
Simon, R., U. Prieffer, and A. Puhler. 1983. A broad host range mobilization system for in vivo genetic engineering: Transposon mutagenesis in gram negative bacteria. Biotechnology 1: 784-790.

Smit, J. 1987. Localizing the subunit pool for the temporally regulated polar pili of Caulobacter crescentus. I. Cell Biol. 105: $1821-1828$.

Sommer, J.M. and A. Newton. 1988. Sequential regulation of developmental events during polar morphogenesis in Caulobacter crescentus: Assembly of pili on swarmer cells requires cell separation. J. Bacteriol. 170: 409-415.

Studier, F.W., A.H. Rosenberg, J.J. Dunn, and J.W. Dubendorff. 1990. Use of T7 RNA polymerase to direct expression of cloned genes. Methods Enzymol. 185: 60-89.

Subbiah, S. and S.C. Harrison. 1989. A method for multiple sequence alignment with gaps. I. Mol. Biol. 209: 539-548.

Tabor, S. and C.C. Richardson. 1985. A bacteriophage T7 RNA polymerase/promoter system for controlled exclusive expression of specific genes. Proc. Natl. Acad. Sci. 82: 10741078.

Towbin, H.T., T. Staehelin, and J. Gordon. 1979. Electrophoretic transfer of proteins from polyacrylamide gels to nitrocellulose sheets: Procedure and some applications. Proc. Natl. Acad. Sci. 76: 4350-4354.

Wright, R. and J. Rine. 1989. Transmission electron microscopy and immunocytochemical studies of yeast: Analysis of HMG-CoA reductase overproduction by electron microscopy. Methods Cell Biol. 31: 473-512. 


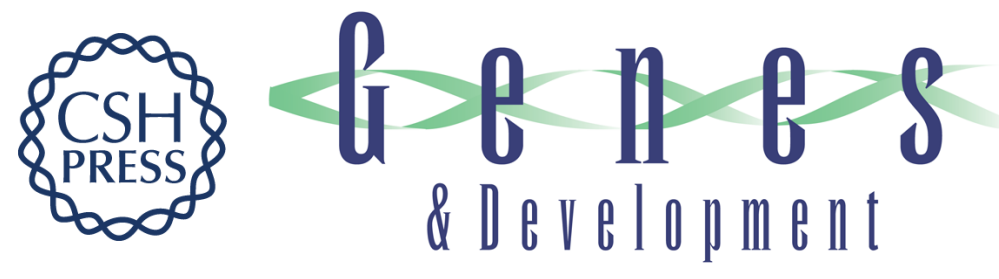

\section{Polar localization of a bacterial chemoreceptor.}

M R Alley, J R Maddock and L Shapiro

Genes Dev. 1992, 6:

Access the most recent version at doi:10.1101/gad.6.5.825

\section{References This article cites 44 articles, 23 of which can be accessed free at:} http://genesdev.cshlp.org/content/6/5/825.full.html\#ref-list-1

\section{License}

Email Alerting

Receive free email alerts when new articles cite this article - sign up in the box at the top Service right corner of the article or click here.

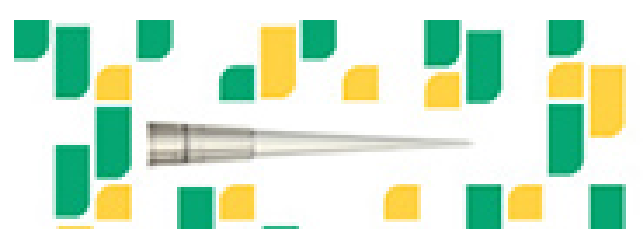

Focused on your science. 